\title{
Optimization of Acetaminophen and Methylparaben Removal within Subsurface Batch Constructed Wetland Systems
}

\author{
Zahraa Hasan Mutar ${ }^{1,2^{*}}$, Ahmed A Mohammed ${ }^{1}$, Israa Abdulwahab Al-Baldawi ${ }^{3}$ \\ 1 Department of Environmental Engineering, College of Engineering, University of Baghdad, Baghdad, Iraq \\ 2 Department of Architecture Engineering, College of Engineering, Wasit University, Wasit, Iraq \\ ${ }^{3}$ Department of Biochemical Engineering, Al-khwarizmi College of Engineering, University of Baghdad, \\ Baghdad, Iraq \\ * Corresponding autor's email: zhassan@uowasit.edu.iq
}

\begin{abstract}
The response surface methodology accompanied by Central Composite Design (CCD) was employed in this study to optimize the Alternanthera spp-based phytoremediation process for the individual removal of acetaminophen and methylparaben. Two operational variables, including concentration (A) $(20,60,100 \mathrm{mg} / \mathrm{L})$ and sampling time (B) $(7,14,21$, and 35 days) were involved in the study for removal efficiency (Y) as response. CCD had required a total of 18 experiments for each compound. Analysis of variance (ANOVA) was conducted to verify the adequacy of the proposed mathematical models and revealed good agreement with the experimental data. The observed $\mathrm{R}^{2}$ values (0.9732 and 0.9870$)$, adjusted $R^{2}(0.9620$ and 0.9816$)$ and predicted $R^{2}(0.9383$ and 0.9721$)$ for $A C$ and MP, respectively, indicated that the developed models were significant at the $95 \%$ probability level. Concentration factor was found to be insignificant in the mathematical models; in contrast, sampling time was found to be of a crucial role. The removal of AC and MP were $89.23 \%$ and $64.48 \%$ under optimum conditions of A $=100 \mathrm{mg} / \mathrm{L}$ and $\mathrm{B}=35$ days respectively. The validation test confirmed the predicted results obtained by Central Composite Design, as the removals achieved under optimum conditions were $91.04 \%$ and $59.17 \%$ for AC and MP, respectively, which were in good agreement with the results proposed by the theoretical design.
\end{abstract}

Keywords: phytoremediation, ornamental plant, constructed wetlands, PPCPs, central composite design.

\section{INTRODUCTION}

Recently, emerging organic contaminants (EOCs) including pharmaceuticals and personal care products (PPCPs) and pesticides have attracted the most attention, after conventional pollutants (such as heavy metals and persistent organic pollutants) were the most threatening to the aquatic environment ( $\mathrm{Xu}$ et al., 2019). PPCPs are widely consumed substances which are frequently detected in surface and ground waters (Hijosa-Valsero et al., 2010). PPCPs have been monitored with concentrations in the range of $\mathrm{ng} / \mathrm{L}$ to $\mathrm{mg} / \mathrm{L}$ at different regions around the world, such as Brazil (Couto et al., 2020), China (Junaid et al., 2019), Czech Republic (Vymazal et al., 2017), India (Williams et al., 2019), Portugal
(Gaffney et al., 2015) and South Africa (Archer et al., 2017). However, there are several practices that would raise the concentrations of PPCPs in the aquatic environment dramatically. For example, Petrie et al. (2016) noted the possibility of intentional or accidental release of high loads of pharmaceuticals (often surplus or expired) into wastewater, and emphasized that the associated facilities (such as pharmacies) may have directly disposed of large quantities of fluoxetine in the aquatic environment.

The growing concern about PPCPs results from their recalcitrant behavior in the receiving ecosystems and the unknown consequences of their continual release (Hijosa-Valsero et al., 2010). PPCPs represent a potential threat, as the presence of such substances in the ecosystems 
may cause antibiotic resistance and endocrine disruptions on humans, livestock and aquatic life (Liu et al., 2019).

Constructed wetlands (CWs) are an affordable choice for wastewater treatment, which are efficiently eliminated or attenuate various contaminants, including PPCPs. Nevertheless, the large area requirements needed to meet the water quality parameters make the application of CWs restricted to wastewater treatment in small urban communities or as tertiary treatments units dealing with the effluents of conventional WWTP (Hijosa-Valsero et al., 2016).

The overall removal or transformation of nutrients and organic contaminants in CWs involve a set of simultaneous physical, chemical and biological processes; where biodegradation, plant uptake and adsorption have the paramount contributions. However, the removal efficiency of CWs is crucially affected by several factors, including wetland type, vegetation type, substrate media, climatic conditions, pollutants concentration and the hydraulic properties of the design (hydraulic retention time and hydraulic loading rate) (Weerakoon et al., 2020).

The optimization step is conducted to seek the best solution for specific conditions, which improves the efficiency of the any process or system (Titah et al., 2018). Several optimization methods have been created for research and industrial projects, and each has its own benefits and weaknesses. One-factor-at-a-time method (OFAT) is a classical optimization methodology which suffers from many weaknesses, including being time-consuming and costly (Sanusi et al., 2016; Ntakiyiruta et al., 2020); further, this method is ineffective in several situations, including predictive studies and evaluation of the interactions between parameters (Darajeh et al., 2016; Sanusi et al., 2016; Ntakiyiruta et al., 2020). Therefore, researchers resorted to statistical and mathematical experimental designs (such as response surface methodology, artificial neural networks and genetic algorithms) as an alternative to the classical approaches (Sanusi et al., 2016).

Response surface methodology (RSM) is an analytical approach which can be applied to identify the optimized operation conditions for a multi-variable structure such as wastewater treatment systems. RSM can be established to evaluate the relationship between the independent and response variables depending on certain criteria. Implementing the RSM approach requires the fewest number of experimental trials, making the optimized processes less time-consuming (Darajeh et al., 2016).

RSM is frequently applied in the wastewater treatment process in order to reach the required aims, particularly for improvement of the pollutant removal efficiency and reduction of operating cost (Ting et al. 2020). However, understanding of the design variables under investigation is essential to achieve an adequate model (Darajeh et al., 2016).

Optimizing the significant parameters is a key step in the phytoremediation process (Sanusi et al., 2016). Several studies have reported the successful application of the RSM models in optimizing phytoremediation process. Central composite design (CCD) was the widely adopted model in most of these studies; for example, Darajeh et al. (2016) used CCD for optimizing the treatment process of palm oil mill effluent (POMSE) via floating $\mathrm{CW}$ by Chrysopogon zizanioides $L$. The researchers choose the removal of chemical oxygen demand (COD) and biological oxygen demand (BOD) as dependent variables, while the concentration of POMSE and the density of the plant represented the influence factors. Optimizing the removal of ammoniacal nitrogen (AN) by Eichhornia crassipes was carried out by CCD, as reported by Ting et al. (2020) with four influence factors $(\mathrm{pH}$, retention time, plant density and salinity) and five responses (AN removal efficiency, biomass growth, COD, BOD and total suspended solids). Thani et al. (2020) employed CCD for optimizing the removal of nickel by Alocasia puber, with nickel concentration and exposure time as independent variables and the removal efficiency as a response. Mojiri et al. (2017) as well, utilized the same model for optimizing the removal of chromium and cadmium from aqueous solutions in constructed wetlands. CCD was also used by Sanusi et al. (2016) for optimizing the degradation of total petroleum hydrocarbon in constructed wetland planted by Paspalum scrobiculatum, where diesel concentration, time and aeration rate represented the independent variables. Besides, another design has been employed, which is Box-Behnken Design (BBD), to optimize the factors that influence the removal of the different contaminants such as diesel (Al-Baldawi et al., 2014) and triclosan (Lam et al., 2020).

In certain circumstances, researchers may have to reduce the number of trials, as in the case of expensive and time consuming experiments. 
In such situations, researchers need to rely on fewer points in the design and this is what the D-optimal design provides (Khan et al., 2016). Khan et al. (2016) confirmed that adopting the D-optimal design reduced the number of experiments by $40.38-50 \%$ compared with the CCD (Khan et al., 2016).

Thus, the objective of this study was to apply RSM accompanied by central composite design to acquire the optimal conditions for the removal of two PPCPs (AC and MP), individually, in subsurface horizontal-flow constructed wetlands using Alternanthera spp. The optimization study would be beneficial for the design of the phytoremediation process to remove AC and MP effectively from the wastewater.

\section{MATERIALS AND METHODS}

\section{Chemicals and plant materials}

High purity Acetaminophen (AC) was obtained from Middle East Laboratories Co. Ltd. (Iraq). Methylparaben (MP) (purity $>99 \%$ ) was purchased from VWR Chemicals (UK). An ornamental plant species (Alternanthera spp) was purchased from Al- Zawraa Park, Baghdad. The plants were rinsed gently, and then acclimatized in tap water for two weeks to favor the growth of roots. Homogenous plants were selected for the experiments.

\section{Set up of the subsurface batch systems}

Two sets of experiments were conducted: one for AC and another for MP. For each set, a glass mesocosms-scale phytoremediation tanks were constructed with the dimensions of $0.3 \times 0.3 \times 0.3 \mathrm{~m}$ and water capacity of $20 \mathrm{~L}$. A schematic description for AC and MP sets are given in Figure 1. Homogenous Alternanthera spp plants were washed gently and acclimated in tap water for two weeks prior to the experiments, then planted at mesocosms with density of 10 plants/mesocosm. Gravel was used as a substrate to a depth of $20 \mathrm{~cm}(5 \mathrm{~cm}$ of coarse gravel $(9.5-13.5 \mathrm{~mm})$ in the bottom, $10 \mathrm{~cm}$ of fine gravel (ø 6.5-9.5 mm) and $5 \mathrm{~cm}$ of fine gravel (ø $2.5-6.5 \mathrm{~mm}$ ) in the top). All mesocosms were placed under the outdoor condition and operated in batch mode. Stock solutions of $1000 \mathrm{mg} / \mathrm{L}$ for both AC and MP were prepared, individually. Then, $5 \mathrm{~L}$ of diluted solution with different concentrations $(20,60$ and $100 \mathrm{mg} / \mathrm{L})$ were fed to each CWL, so that the water level was controlled within the gravel surface to simulate a horizontal subsurface constructed wetlands (SSB-CWL). Tap water was added to the tanks regularly to compensate the loss of water and maintain a constant water level. Finally, the effluent from each CWL was collected throughout the 35-day exposure and analyzed for AC and MP.

\section{Analysis of AC and MP}

The water samples were first filtered through a $0.45 \mu \mathrm{m}$ syringe filter, then directly analyzed via UV-visible spectrophotometer (UV-1800, Shimadzu, Japan) to quantify the concentrations of AC (based on USP 29 assay) and MP (based on Piovesan et al. (2018)), as described in supplementary materials. The absorbance values were qualified at maximum wavelength of 242 and $255 \mathrm{~nm}$ for AC and MP, respectively, then the concentration of both compounds was calculated.

The removal efficiency for the target compounds were calculated based on the initial and final concentrations in the synthetic wastewater, according to equation (1):
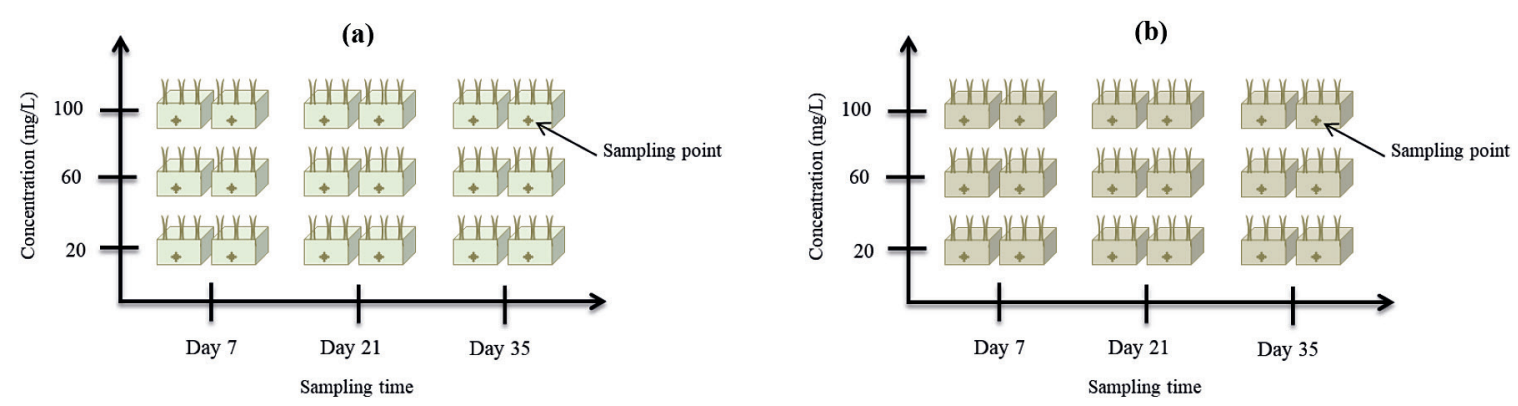

Figure 1. Schematic diagram of the mesocosm-scale CWLs: (a) AC and (b) MP 


$$
\mathrm{RE} \%=\frac{\mathrm{C}_{\mathrm{i}}-\mathrm{C}_{\mathrm{t}}}{\mathrm{C}_{\mathrm{i}}} \times 100
$$

where: $R E$ is the removal efficiency $(\%)$; $C_{i}$ and $C_{t}(\mathrm{mg} / \mathrm{L})$ are the pollutant concentration initially and through time.

\section{Optimizing the removal of $\mathrm{AC}$ and MP with the central composite design}

RSM was performed to estimate the relations existing between two of experimental variables namely concentration of the contaminant in wastewater (A) and sampling time (B), with the measured responses, namely the removal efficiency by Alternanthera spp (Y).

Central composite design (CCD) was applied as the Design of Expert (Version 6.0.1, Stat-Ease Inc., Minneapolis, MN, USA) for data interpretation and regression modeling, in which a total of 18 runs were conducted for each AC and MP, separately, with 2 center points, 16 axial points and $\alpha=1$. The experiments included a duplicate for each run to evaluate the magnitude of the random error. The experimental design was performed with the relevant factors at three levels $(+1,0$, $-1)$ : concentration $(20,60$, and $100 \mathrm{mg} / \mathrm{L})$ and sampling time $(7,21$, and 35 days) as indicated in Table 1. The relation between the independent parameters and the responses was mathematically described by the quadratic model, as shown in Eq. (2) (Al-Baldawi et al., 2014):

$$
\begin{aligned}
Y= & \beta_{0}+\beta_{1} A+\beta_{2} B+\beta_{11} A^{2}+ \\
& +\beta_{22} B^{2}+\beta_{12} A B+\varepsilon
\end{aligned}
$$

where: $Y$ is the predicted response (removal efficiency for AC or MP);

$A$ and $\mathrm{B}$ are the independent variables,

$A^{2}$ and $B^{2}$ are the square effects and $\mathrm{AB} \mathrm{s}$ the interaction effects;

$\beta_{0}$ is the regression constant, $\beta_{1}$ and $\beta_{2}$ are the linear coefficients,

Table 1.Parameters involved in the experimentaldesign.

\begin{tabular}{|l|c|c|c|c|}
\hline \multirow{2}{*}{ Parameters } & \multirow{2}{*}{ Factors } & \multicolumn{4}{|c|}{ Range and levels } \\
\cline { 3 - 5 } & & -1 & 0 & +1 \\
\hline Concentration (mg/L) & A & 20 & 60 & 100 \\
\hline Sampling time (day) & B & 7 & 21 & 35 \\
\hline
\end{tabular}

$\beta_{11}$ and $\beta_{22}$ are quadratic coefficients and $\beta_{12}$ is the interaction coefficient; $\varepsilon$ is the random error.

The fitness of the proposed models was assessed by conducting analysis of variance (ANOVA), where a valid model must achieve a significant $\mathrm{F}$-value and $\mathrm{P}$-value, while the value with lack of fit must be insignificant (Al-Baldawi et al., 2014; Titah et al., 2018). Diagnostics plots were also assessed to verify the validity of the models. Further evaluation of the proposed models was conducted by testing the coefficient of determination $\left(\mathrm{R}^{2}\right)$, adjusted coefficient of determination $\left(\mathrm{R}^{2}{ }_{\text {adjust }}\right)$ and predicted coefficient of determination $\left(\mathrm{R}^{2}\right.$ predict $)$, where the correlations close to 1.0 indicate a good relationship between the expected and the actual values of the response (Al-Baldawi et al., 2014; titah et al., 2018). Moreover, the effects of involved parameters were also compared using $3 \mathrm{D}$ response surface plots.

Optimization was performed to identify the optimum conditions for achieving the highest removal efficiency for AC and MP.

\section{Validation of the models}

In order to verify the optimized results, two additional mesocosms, planted with Alternanthera spp, were used, in which the predicted optimum conditions of the independent parameters (concentration and sampling time) proposed by CCD were simulated. Then, the actual results attained in this step were compared with the predicted optimal values.

\section{RESULTS AND DISCUSSION}

\section{Developing the quadratic models by central composite design}

CCD was performed to model and optimize the removal of AC and MP, individually, by $\mathrm{Al}$ ternanthera spp from synthetically prepared wastewater. The analysis was carried out at a significance level of 5\%. The actual results obtained from the experimental design (represented in Figure 2) were fitted to a quadratic model through multiple regression analysis, where the positive coefficient values represented a synergistic effect, while the negative coefficient values represented an antagonistic effect. The quadratic models that 
a)

$A C$

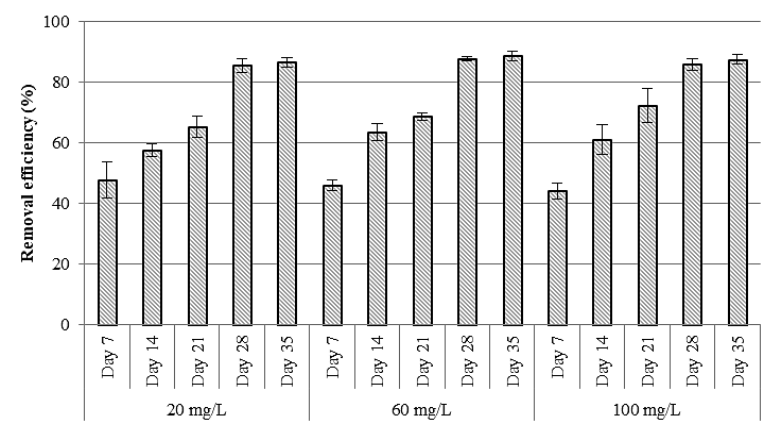

b)

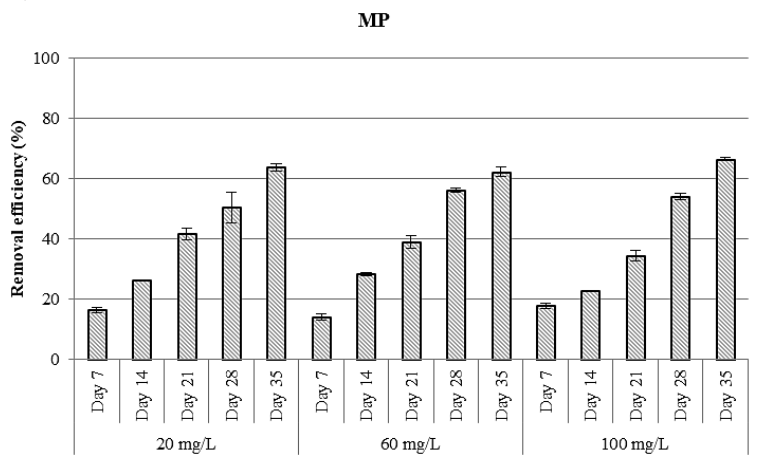

Figure 2. Removal of AC and MP from the synthetically prepared wastewater throughout a 35-days experiment

relate the removal rates (response) and the independent variables were developed by CCD and described in terms of the coded parameters as given in Equation 2 and 3.

$$
\begin{gathered}
Y_{A C}=69.10+0.74 A+20.81 B-0.58 A^{2}- \\
-1.97 B^{2}+1.13 A B \\
Y_{M P}=37.31-0.51 A+24.03 B+1.59 A^{2}+ \\
+1.71 B^{2}+0.35 A B
\end{gathered}
$$

where: $Y_{A C}$ and $Y_{M P}-$ removal efficincy (\%) for $\mathrm{AC}$ and MP, respectively,

$A$ - concentration $(\mathrm{mg} / \mathrm{L})$ of AC or MP,

$B$-sampling time (day).
The actual removal rates, in addition to the predicted response values for $\mathrm{AC}$ and MP sets, are presented in Table 2. The highest and lowest AC removal rates acheived during the experiments were $89.69 \%$ and $42.21 \%$, respectively; while the maximum and minimum removal rates predicted by CCD were $89.23 \%$ and $45.34 \%$, respectively. As for MP, the highest and lowest removal rates were $66.91 \%$ and $13.33 \%$, respectively; while the maximum and minimum removal rates predicted by CCD were $64.80 \%$ and $14.99 \%$, respectively. The agreement of the actual data with the responses predicted by RSM raises the reliability and applicability of the proposed model (Ozturk et al., 2021). In this study, there is a satisfactory correlation between the predicted output values

Table 2. Central composite design matrix for actual and predicted responses of AC and MP

\begin{tabular}{|c|c|c|c|c|c|c|}
\hline \multirow{2}{*}{ Run } & \multirow{2}{*}{$\begin{array}{c}\text { Concentration } \\
(\mathrm{mg} / \mathrm{L})\end{array}$} & \multirow{2}{*}{$\begin{array}{c}\text { Sampling time } \\
(\text { Day })\end{array}$} & & \multicolumn{4}{|c|}{ Removal (\%) } \\
\cline { 4 - 6 } & & & \multicolumn{2}{|c|}{ Acetaminophen } & \multicolumn{2}{|c|}{ Methylparaben } \\
\cline { 4 - 6 } & & Actual & Predicted & Actual & Predicted \\
\hline 1 & 20.00 & 7.00 & 43.45 & 46.13 & 37.58 & 37.31 \\
\hline 2 & 60.00 & 35.00 & 87.52 & 87.95 & 64.50 & 64.80 \\
\hline 3 & 20.00 & 21.00 & 62.77 & 67.78 & 13.33 & 14.99 \\
\hline 4 & 60.00 & 21.00 & 69.53 & 69.10 & 66.05 & 64.49 \\
\hline 5 & 20.00 & 35.00 & 87.56 & 85.49 & 66.91 & 64.49 \\
\hline 6 & 20.00 & 35.00 & 85.51 & 85.49 & 15.80 & 17.44 \\
\hline 7 & 100.00 & 21.00 & 68.23 & 69.26 & 33.06 & 38.39 \\
\hline 8 & 100.00 & 21.00 & 76.16 & 69.26 & 16.86 & 17.44 \\
\hline 9 & 60.00 & 7.00 & 44.78 & 46.32 & 14.86 & 14.99 \\
\hline 10 & 100.00 & 7.00 & 42.21 & 45.34 & 40.16 & 39.41 \\
\hline 11 & 60.00 & 35.00 & 89.69 & 87.95 & 61.06 & 63.06 \\
\hline 12 & 60.00 & 21.00 & 67.90 & 69.10 & 40.59 & 37.31 \\
\hline 13 & 60.00 & 7.00 & 47.32 & 46.32 & 17.10 & 15.72 \\
\hline 14 & 100.00 & 35.00 & 86.46 & 89.23 & 62.85 & 64.80 \\
\hline 15 & 20.00 & 21.00 & 67.69 & 67.78 & 35.73 & 38.39 \\
\hline 16 & 20.00 & 7.00 & 51.83 & 46.13 & 63.30 & 63.06 \\
\hline 17 & 100.00 & 7.00 & 46.00 & 45.34 & 18.36 & 15.72 \\
\hline 18 & 100.00 & 35.00 & 88.60 & 89.23 & 43.12 & 39.41 \\
\hline
\end{tabular}


calculated using the suggested quadratic models and the actual experimental values, which indicated the accuracy of these models. Thus, the proposed models showed good prediction ability under the considered conditions.

\section{Fitting and analysis of variance for response surface quadratic models}

A "good fit" model is necessary to avoid unclear or inadequate results in the optimization process (Al-Baldawi et al., 2014; Ozturk et al., 2021). Regression analysis, in addition to the diagnostics plot, were adopted to assess the fitness of the developed models. ANOVA was conducted to test the significance and adequacy of the suggested mathematical models as a whole, in addition to the individual terms in the models.

The ANOVA results for the proposed models (AC-removal model and MP-removal model) are listed in Table 3. F-test was considered to assess the significance of the proposed models. The criterion that must be met for the acceptability and reliability of the model is an increase in the Fvalue of the proposed model in conjunction with a decrease in P-value (Bajpai et al., 2020).
The F-value for AC and MP removal models were 87.00 and 182.45 , respectively, indicating that the models are significant and can effectively explain most of the variation in the response (AlBaldawi et al., 2014). This refers to only $0.01 \%$ chance for "Model F-Value" this large to occur due to noise. Besides, the associated P-value was considered to decide whether the F-value was large enough to confirm the statistical significance (Al-Baldawi et al., 2014; Ewadh et al., 2019). The P-values for the AC and MP removal models were found to be lower than 0.05 (particularly, < 0.0001 for both AC and MP), indicating that both models were statistically significant at the $95 \%$ probability level.

The lack of fit F-value of 1.46 for the AC model revealed that the lack of fit is not significant, thus the variations of the data around the fitted model were not significant, compared to the pure error. Nonsignificant lack of fit is good, as the model approaches perfect fitness referred to the significance of the model (Bayuo et al., 2020). Moreover, there was a $29.02 \%$ chance that a "Lack of Fit F-value" this large could have occured due to noise. In contrast, the lack of fit F-value for MP model was 11.27 , impling that the lack of fit was

Table 3. ANOVA analysis of the proposed quadratic models for AC and MP removal from wastewater

\begin{tabular}{|c|c|c|c|c|c|c|}
\hline Source & Sum of squares & DF & Mean square & F value & Prob $>$ F & \\
\hline \multicolumn{7}{|c|}{ Acetaminophen } \\
\hline Model & 5231.55 & 5 & 1046.31 & 87.00 & $<0.0001$ & significant \\
\hline A & 6.54 & 1 & 6.54 & 0.54 & 0.4749 & \\
\hline B & 5197.84 & 1 & 5197.84 & 432.20 & $<0.0001$ & \\
\hline$A^{2}$ & 1.37 & 1 & 1.37 & 0.11 & 0.7417 & \\
\hline $\mathrm{B}^{2}$ & 15.52 & 1 & 15.52 & 1.29 & 0.2781 & \\
\hline$A B$ & 10.28 & 1 & 10.28 & 0.85 & 0.3735 & \\
\hline Residual & 144.32 & 12 & 12.03 & & & \\
\hline Lack of Fit & 47.18 & 3 & 15.73 & 1.46 & 0.2902 & not significant \\
\hline Pure error & 97.14 & 9 & 10.79 & & & \\
\hline Cor Total & 5375.87 & 17 & & & & \\
\hline \multicolumn{7}{|c|}{ Methylparaben } \\
\hline Model & 6955.45 & 5 & 1391.09 & 182.45 & $<0.0001$ & significant \\
\hline$A$ & 3.09 & 1 & 3.09 & 0.40 & 0.5365 & \\
\hline $\mathrm{B}$ & 6929.60 & 1 & 6929.60 & 908.88 & $<0.0001$ & \\
\hline$A^{2}$ & 10.07 & 1 & 10.07 & 1.32 & 0.2729 & \\
\hline $\mathrm{B}^{2}$ & 11.71 & 1 & 11.71 & 1.54 & 0.2389 & \\
\hline$A B$ & 0.99 & 1 & 0.99 & 0.13 & 0.7254 & \\
\hline Residual & 91.49 & 12 & 7.62 & & & \\
\hline Lack of fit & 72.26 & 3 & 24.09 & 11.27 & 0.0021 & significant \\
\hline Pure error & 19.23 & 9 & 2.14 & & & \\
\hline Cor total & 7046.94 & 17 & & & & \\
\hline
\end{tabular}


significant, which is unacceptable. There was only a $0.21 \%$ chance that a "Lack of Fit F-value" this large could occur due to noise.

Further statistical measures, including the coefficients of determination $\left(\mathrm{R}^{2}\right)$ and adjusted $\mathrm{R}^{2}$, had to be evaluated to ensure the adequacy of the suggested models (Table 4). ANOVA results confirmed the significance of the models with good $\mathrm{R}^{2}(0.973$ and 0.987$)$ and adjusted $\mathrm{R}^{2}(0.962$ and 0.981 ) values for AC and MP, respectively, which indicates that the proposed models could explain $97.3 \%$ and $98.7 \%$ of the response variability for AC and MP, respectively (Ting et al., 2020). Further, the predicted $\mathrm{R}^{2}$ values of 0.938 and 0.972 for AC and MP, respectively, showed good agreement with the adjusted $\mathrm{R}^{2}$ of both models. The obtained values of $\mathrm{R}^{2}$, adjusted $\mathrm{R}^{2}$ and predicted $\mathrm{R}^{2}$ were close to 1 , demonstrating a good fitness of the models in the experimental data (Hamad, 2020). "Adeq Precision" quantifies the signal to noise ratio, a ratio greater than 4 is preferred (AlBaldawi et al., 2014; Bajpai et al., 2020; Wang et al., 2020). The signal to noise ratio achieved in the present study was 21.92 for AC and 31.24 MP, indicating an adequate signal.

Regarding the concentration factor represented by term A, the low F-value of 0.54 and 0.40 for AC and MP models, respectively, along with the high P-value $(>0.1)$ for both models indicated

Table 4. Statistics of the proposed quadratic models

\begin{tabular}{|l|c|c|}
\hline \multirow{2}{*}{ Statistical parameters } & \multicolumn{2}{|c|}{ Values of developed models } \\
\cline { 2 - 3 } & $\mathrm{AC}$ & $\mathrm{MP}$ \\
\hline R-squared & 0.973 & 0.987 \\
\hline Adjusted R-squared & 0.962 & 0.981 \\
\hline Predicted R-squared & 0.938 & 0.972 \\
\hline Adeq precision & 21.92 & 31.24 \\
\hline
\end{tabular}

a)

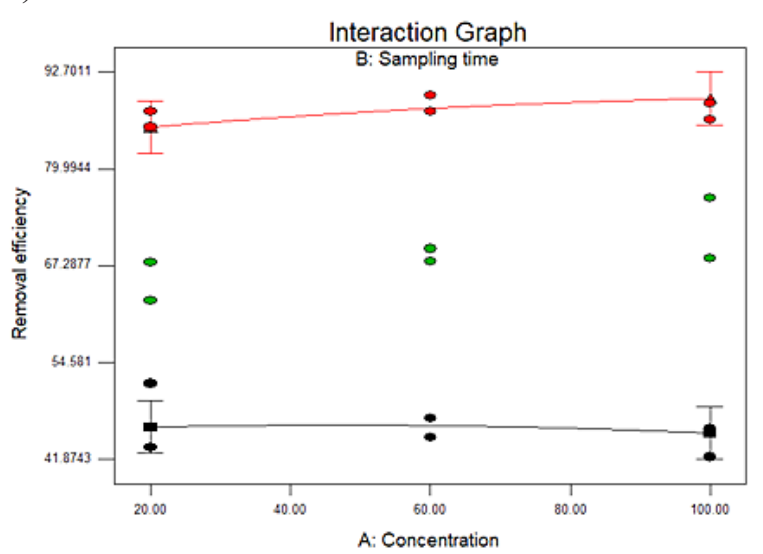

that this factor was not significant for both AC and MP removal models. In contrast, the sampling time (term B) was found to be significant for both models and had a substantial impact on the responses. Further, the quadratic effects $\left(\mathrm{A}^{2}\right.$ and $\mathrm{B}^{2}$ ), in addition to the intraction effects $(\mathrm{AB})$ were not significant in both models. Figure 3 represents the contour plots for the interactive effect of terms $\mathrm{A}$ and $\mathrm{B}$ on the response (Y) for the $\mathrm{AC}$ and MP models.

The diagnostics plots of the models statistical properties are illustrated in Figures 4 and 5. Analyzing normal plot of residuals is of particular importance, as it contributs to verifying the normality assumption needed to verify statistical modeling (Al-Baldawi et al., 2014). The diagnostic of normal residuals (Figures $4 \mathrm{a}$ and $5 \mathrm{a}$ ) confirms that the probability for both $\mathrm{AC}$ and MP removal models follows an acceptable linear trend. The linearity of studentized residuals graph points out to the normality of the error distribution. In turn, the points with nonlinear path reffer to abnormal error distribution, thus correction of the original data might be recommended (Teiri et al., 2020). As shown in Figures $4 b$ and 5b, representing the plot of the studentized residuals versus the predicted response values, the error values were within the specified standard range (indicated by the green lines) which were calculated based on the normal distribution of the error and the standard deviation. Checking the diagnostic of the number of studentized residuals per run provides a close assessment for the number of trials with high errors (Teiri et al., 2020). Figures $4 c$ and 5c, representing the number of studentized residuals per run demonstrated that the error for all points is also within the specified standard range. The plot of the actual versus the predicted responses

b)

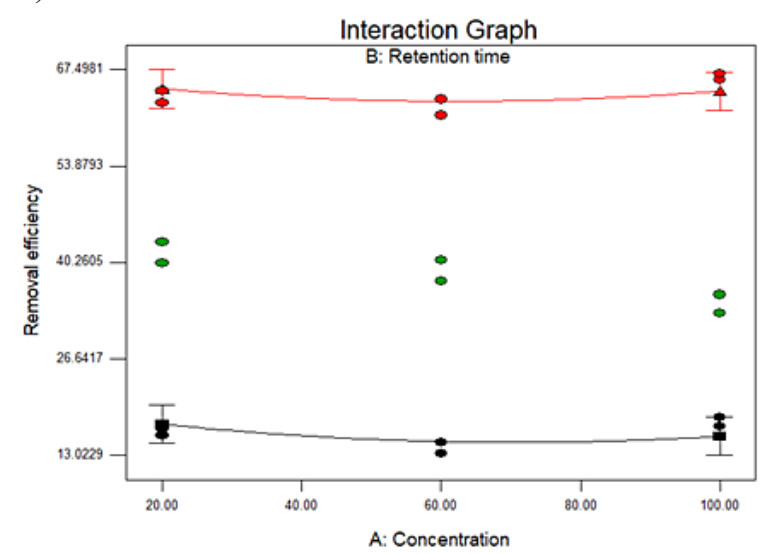

Figure 3. Interactive effects of concentration and sampling time $(A B)$ on removal efficiency $(Y)$ : (a) AC (b) MP 
a)

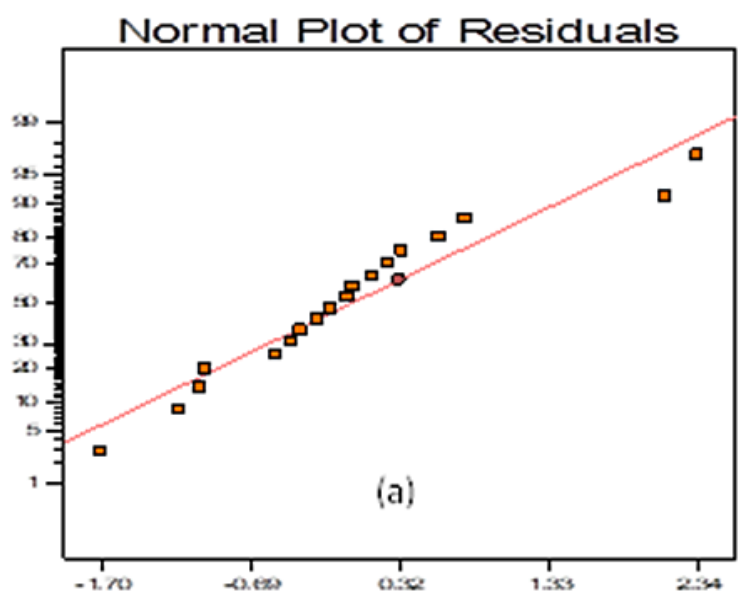

c)

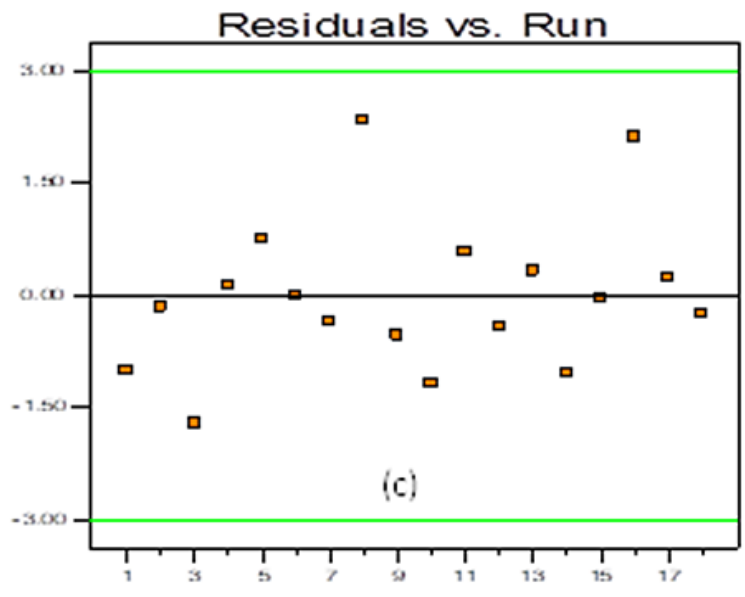

b)

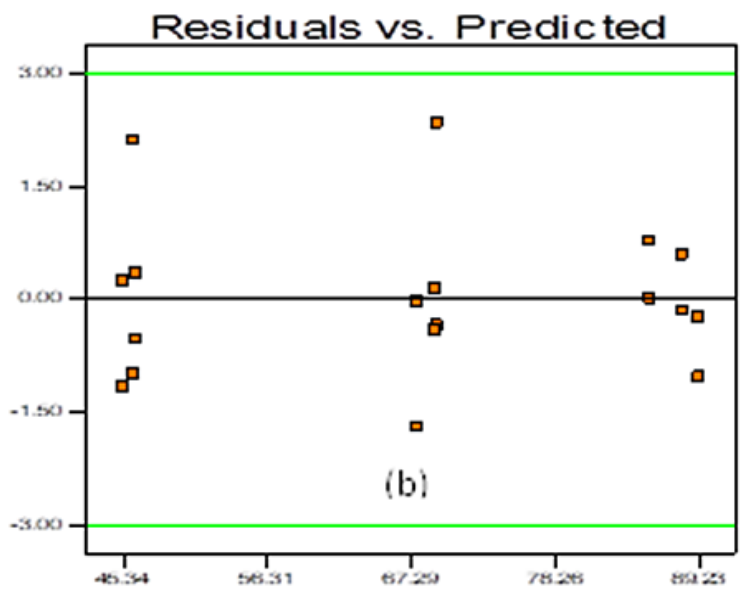

d)

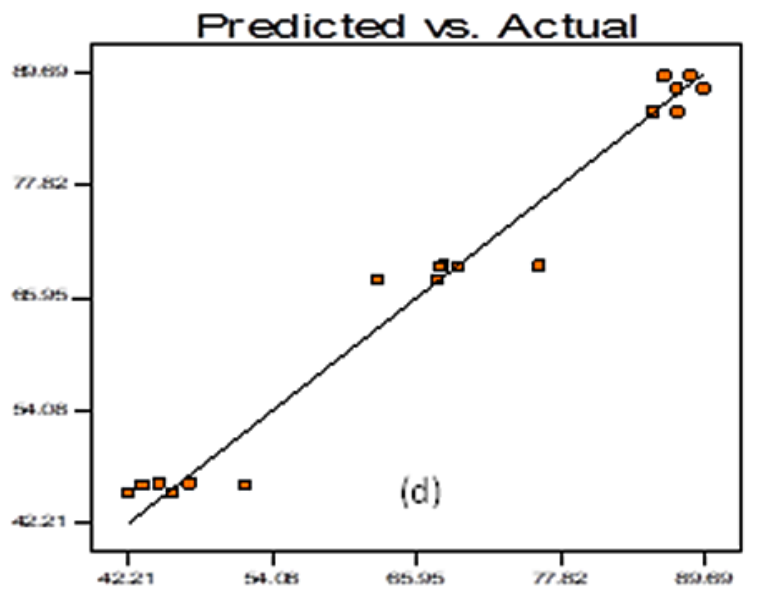

Figure 4. Diagnostic plots for AC removal representing (a) studentized residuals versus the normal probability, (b) studentized residuals versus predicted response values, (c) run versus studentized residuals, (d) actual responses values versus the predicted response values

(Figures $4 \mathrm{~d}$ and $5 \mathrm{~d}$ ) reveals that the predicted values fitted well with the actual values.

\section{Optimization of operational conditions}

The impact of parameters, namely, concentration and sampling time on the removal of $\mathrm{AC}$ and MP were analyzed to achieve maximum efficiency of phytoremediation by using Alternanthera spp. The optimization process aims to specify the optimum operation conditions needed for maximizing removal for both $\mathrm{AC}$ and $\mathrm{MP}$ from wastewater. The desirability function methodology was adopted for this purpose. The variables of AC and MP concentrations were set at the maximum $(100 \mathrm{mg} / \mathrm{L})$ while sampling time was set in range of the experiment. By conducting the function of numerical optimization in the Design Expert software, desirability of 0.995 and $0.977 \%$ was found for the maximum AC and MP removal, respectively, as shown in Figure 6. The maximum AC and MP removals from wastewater were $89.23 \%$ and $64.48 \%$, respectively, under the optimized conditions of: concentration $(\mathrm{A}=$ $100 \mathrm{mg} / \mathrm{L})$ and sampling time $(\mathrm{B}=35$ days $)$.

In Figure 7, the influence of the investigated parameters on AC and MP removal are illustrated as $3 \mathrm{D}$ response surface plots. It was observed that concentration ranging between 20 to $100 \mathrm{mg} / \mathrm{L}$ led to a steady removal from wastewater for both AC and MP. This might be attributed to the relatively high levels of concentrations. The effect of sampling time (B) was an increase in the response within 7 to 35 days. This confirmed that longer sampling time of phytoremediation reduces more $\mathrm{AC}$ and MP concentration in wastewater and indicates that the equations effectively represent the relationship between the response (AC and MP removal from wastewater) and the significant input variables. 
a)

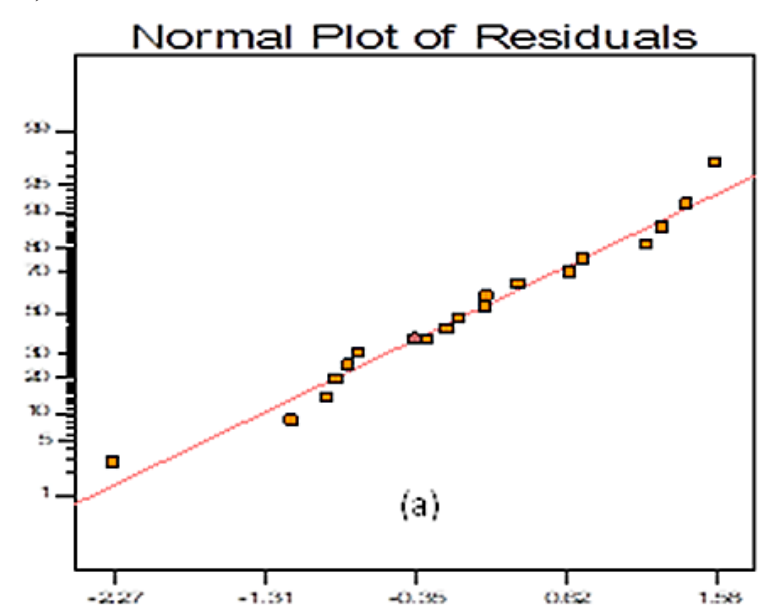

c)

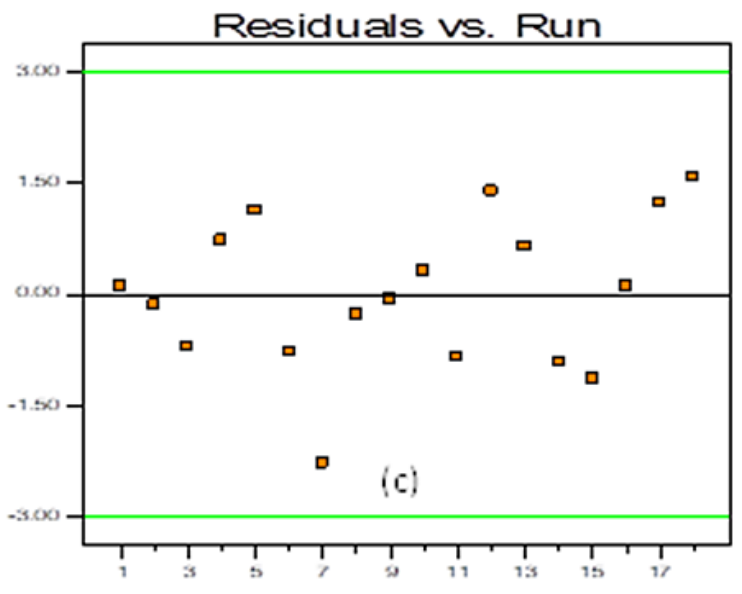

b)

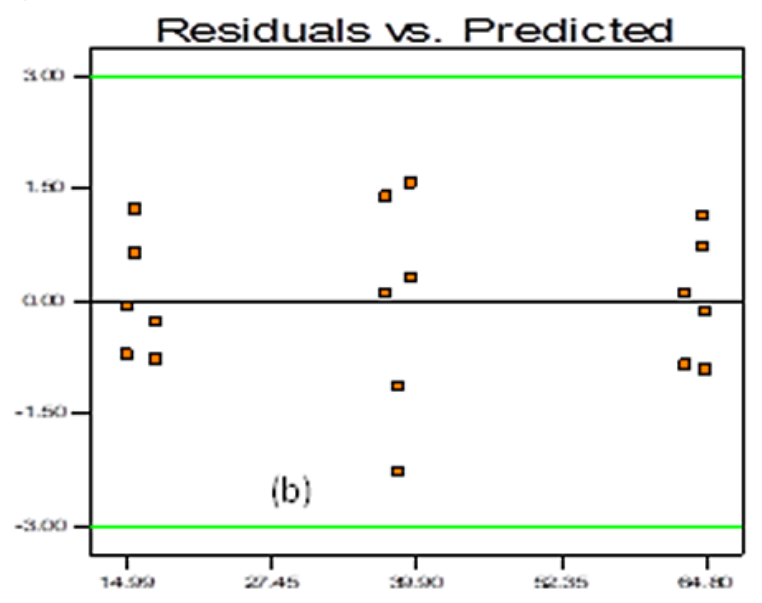

d)

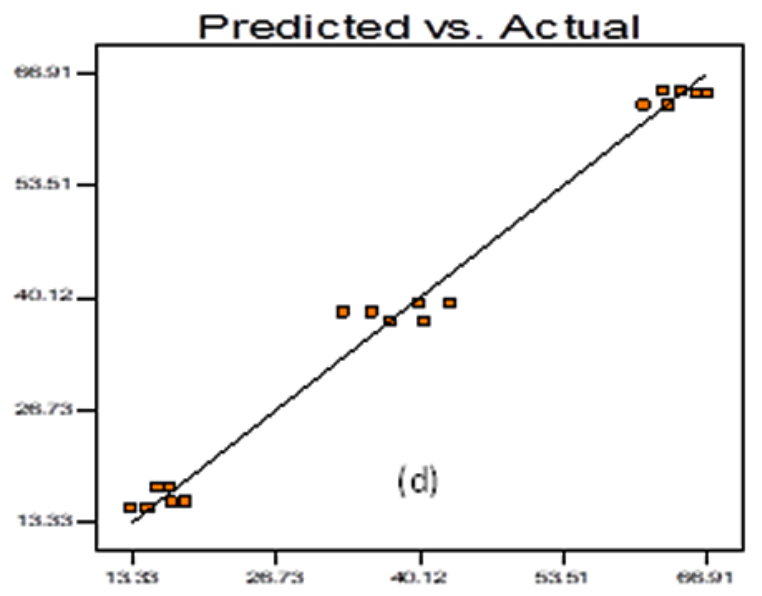

Figure 5. Diagnostic plots for MP removal representing (a) studentized residuals versus the normal probability, (b) predicted versus studentized residuals, (c) run versus studentized residuals, (d) actual responses values versus the predicted response values

a)
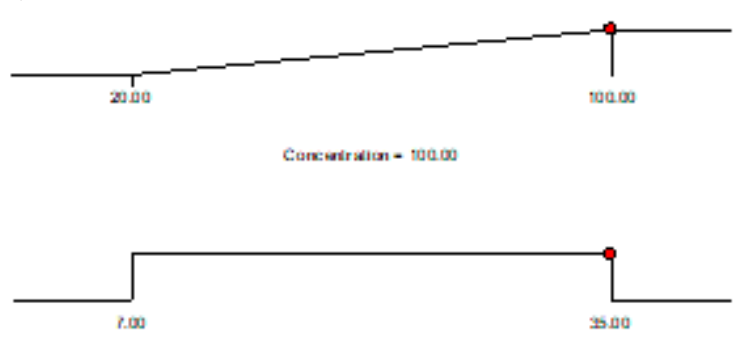

Sartosing lume - Sico

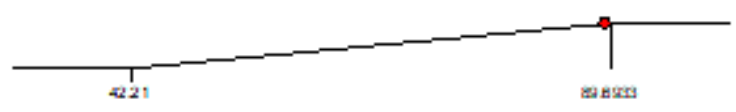

a Desirsiity $=0.995$

b)
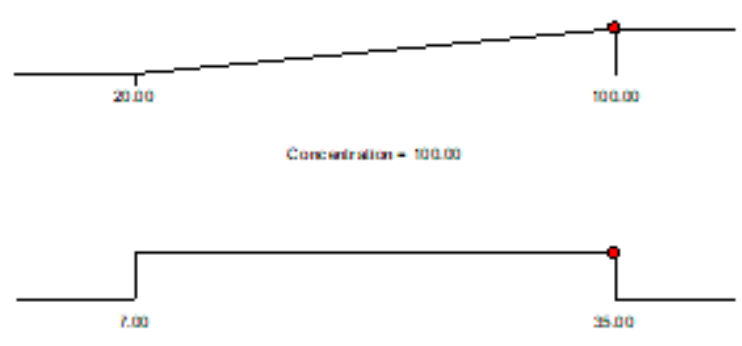

Batianian lime - Som

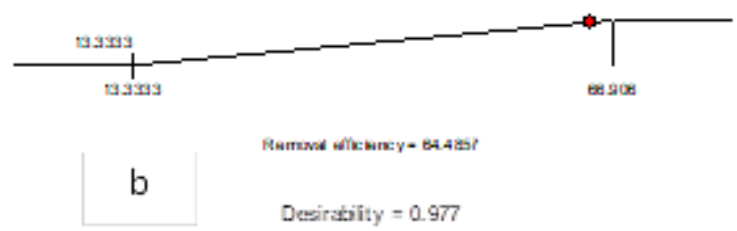

Figure 6. Desirability slope for numerically-optimized conditions: (a) AC and (b) MP 
a)

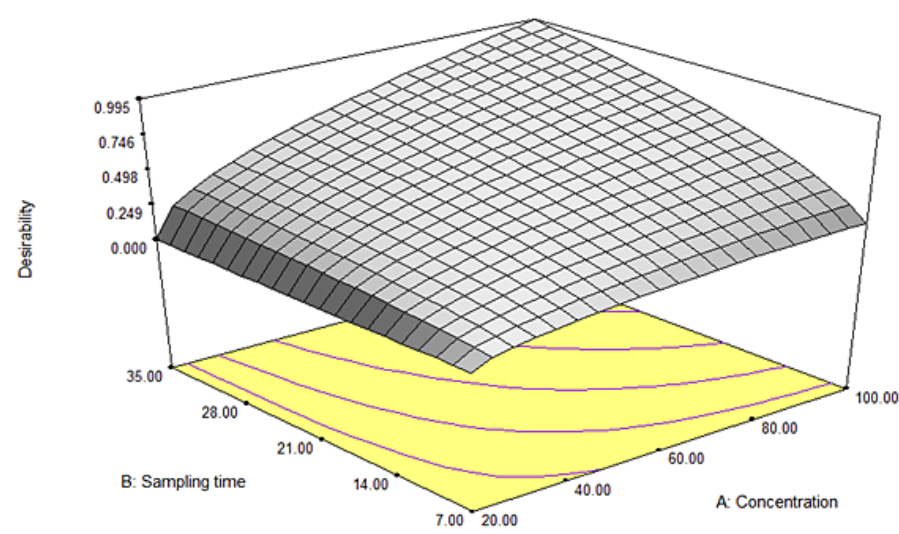

b)

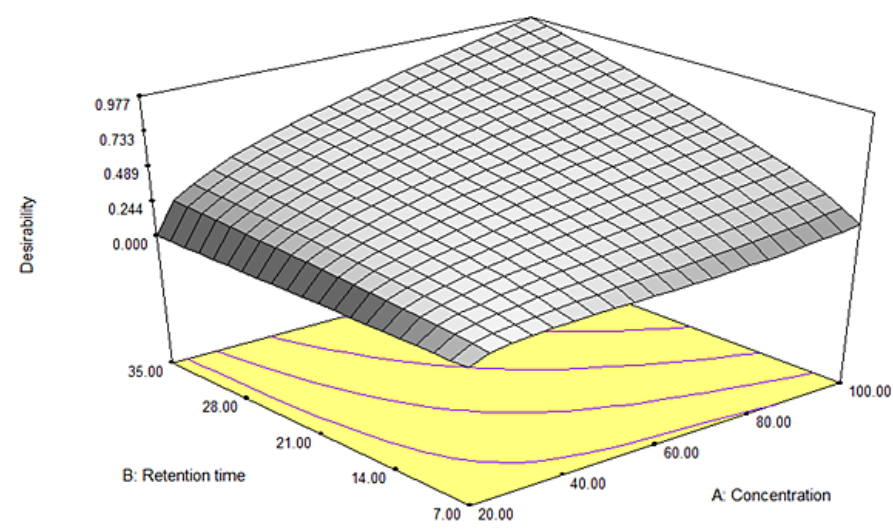

Figure 7. Optimum conditions for: (a) AC removal (b) MP removal

\section{Validation}

Further experiments were conducted in order to validate the obtained optimum conditions created by RSM. This run validated the accuracy of the model and reported $91.04 \%$ and $59.17 \%$ of AC and MP removal, respectively, which closely agreed with the predicted results attained by CCD with the error of $5 \%$ and $7 \%$, respectively. The high agreement between the experimental and theoretical response indicates the precision of the response surface models (Kumari and Gupta, 2019).

\section{CONCLUSIONS}

Central Composite Design was employed to build response surface models and optimize the removal of AC and MP from wastewater via phytoremediation by Alternanthera spp at mesocosm-scale constructed wetlands. The coefficients of determination $\left(\mathrm{R}^{2}\right)$ and adjusted $\mathrm{R}^{2}$ for the proposed models were close to 1 which confirms the significance of the regression models to predict the responses. The predicted values obtained by the models exhibited good agreement with the experimental results. Sampling time had a significant influence on the removal process for both $\mathrm{AC}$ and MP, whereas the concentration of target compounds did not show any significant influence. According to the results of this study, phytoremediation represents a feasible treatment technology for the removal of PPCPs from contaminated wastewater that can be successfully improved and optimized via the response surface methodology approaches.

\section{Acknowledgements}

The authors would like to thank the College of Engineering and Al-Khwarizmi College of Engineering, University of Baghdad, College of Engineering, Wasit University and Ministry of Higher Education, Iraq for supporting this research project. 


\section{REFERENCES}

1. Al-Baldawi I.A.W., Abdullah S.R.S., Hasan H.A., Suja F., Anuar N., Mushrifah I. 2014. Optimized conditions for phytoremediation of diesel by Scirpus grossus in horizontal subsurface flow constructed wetlands (HSFCWs) using response surface methodology. J. Environ. Manage., 140, 152-159. http:// dx.doi.org/10.1016/j.jenvman.2014.03.007

2. Archer E., Petrie B., Kasprzyk-Hordern B., Wolfaardt G.M., 2017. The fate of pharmaceuticals and personal care products (PPCPs), endocrine disrupting contaminants (EDCs), metabolites and illicit drugs in a WWTW and environmental waters. Chemosphere, 174, 437-446. https://doi.org/10.1016/j. chemosphere.2017.01.101

3. Bajpai M., Singh Katoch S., Singh M. 2020. Optimization and economical study of electrocoagulation unit using CCD to treat real graywater and its reuse potential. Environ. Sci. Pollut. Res., 27, 42040-42050. https://doi.org/10.1007/ s11356-020-10171-x

4. Bayuo J., Abukari M.A., Pelig-Ba K.B. 2020 Optimization using central composite design (CCD) of response surface methodology (RSM) for biosorption of hexavalent chromium from aqueous media. Appl. Water Sci 10, 135. https://doi. org/10.1007/s13201-020-01213-3

5. Couto C.F., Santos A.V., Amaral M.C.S., Lange L.C., de Andrade L.H., Foureaux A.F.S., Fernandes B.S. 2020. Assessing potential of nanofiltration, reverse osmosis and membrane distillation drinking water treatment for pharmaceutically active compounds (PhACs) removal. J. Water Process Eng. 33, 101029. https://doi.org/10.1016/j.jwpe.2019.101029

6. Darajeh N., Idris A., Masoumi H.R.F., Nourani A., Truong P., Sairi N.A. 2016. Modeling BOD and COD removal from Palm Oil Mill Secondary Effluent in floating wetland by Chrysopogon zizanioides (L.) using response surface methodology. J. Environ. Manage. 181, 343-352. http://dx.doi. org/10.1016/j.jenvman.2016.06.060

7. Ewadh H.M., Abdullah S.R.S., Hasan H.A., Anwar N. 2019. Optimized conditions for pharmaceuticals and personal care products removal by ozonation using response surface methodology. Int. J. Pharm. Qual. Assur. 10, 90-99. https://doi.org/10.25258/ ijpqa.10.1.15

8. Gaffney V.J., Almeida C.M.M., Rodrigues Al., Ferreira E., Benoliel M.J., Cardoso V.V. 2015. Occurrence of pharmaceuticals in a water supply system and related human health risk assessment. Water Res. 72, 199-208. https://doi.org/10.1016/j. watres.2014.10.027

9. Hamad M.T.M.H. 2020. Comparative study on the performance of Typha latifolia and Cyperus
Papyrus on the removal of heavy metals and enteric bacteria from wastewater by surface constructed wetlands. Chemosphere 260, 127551. https://doi. org/10.1016/j.chemosphere.2020.127551

10. Hijosa-Valsero M., Matamoros V., Martín-Villacorta J., Bécares E., Bayona J.M. 2010. Assessment of Full-Scale Natural Systems for the Removal of PPCPs from Wastewater in Small Communities. Water Res. 44, 1429-39. https://doi.org/10.1016/j. watres.2009.10.032

11. Hijosa-Valsero M., Reyes-Contreras C., Domínguez C., Becares E., Bayona J.M. 2016. Behaviour of pharmaceuticals and personal care products in constructed wetland compartments: Influent, effluent, pore water, substrate and plant roots. Chemosphere, $145,508-517$.

12. Junaid M., Wang Y., Hamid N., Deng S., Li W.G., Pei D.S. 2019. Prioritizing selected PPCPs on the basis of environmental and toxicogenetic concerns: A toxicity estimation to confirmation approach. J. Hazard. Mater. 380, 120828. https://doi. org/10.1016/j.jhazmat.2019.120828

13. Khan A., Do J., Kim D. 2016. Experimental optimization of high strength self-compacting concrete based on D-Optimal design. J. Constr. Eng. Manage. 143, 04016108. http://10.1061/(ASCE) CO.1943-7862.0001230

14. Kumari M., Gupta S. 2019. Response surface methodological (RSM) approach for optimizing the removal of trihalomethanes (THMs) and its precursor's by surfactant modified magnetic nanoadsorbents (sMNP)- An endeavor to diminish probable cancer risk. Sci. Rep. 9,18339. https://doi. org/10.1038/s41598-019-54902-8

15. Lam K.Y., Lieu S.N., Benoit P., Passeport E. 2020. Optimizing Constructed Wetlands for Safe Removal of Triclosan: A Box-Behnken Approach. Environ. Sci. Technol., 54, 225-234. http://10.1021/acs. est.9b05325

16. Liu M., Yin H., Wu Q. 2019. Occurrence and Health Risk Assessment of Pharmaceutical and Personal Care Products (PPCPs) in Tap Water of Shanghai. Ecotoxicol. Environ. Saf., 183, 109497. https://doi. org/10.1016/j.ecoenv.2019.109497

17. Mojiri A., Tajuddin R.M., Ahmad Z., Ziyang L., Aziz H.A., Amin N.M. 2017. Chromium(VI) and cadmium removal from aqueous solutions using the BAZLSC/cockle shell constructed wetland system: optimization with RSM. Int. J. Environ. Sci. Technol., 15, 1949-1956. http://10.1007/ s13762-017-1561-2

18. Ntakiyiruta P., Briton B.G.H., Nsavyimana G., Adouby K., Nahimana D., Ntakimazi G., Reinert L. 2020. Optimization of the phytoremediation conditions of wastewater in post-treatment by Eichhornia crassipes and Pistia stratiotes: kinetic model for 
pollutants removal. Environ. Technol., 1-14. https:// doi.org/10.1080/09593330.2020.1852445

19. Ozturk D., Dagdas E., Fil B.A., Bashir M.J.K. 2021. Central composite modeling for electrochemical degradation of paint manufacturing plant wastewater: One-step/two-response optimization. Environ. Technol. Innov., 21, 101264. https://doi. org/10.1016/j.eti.2020.101264

20. Petrie B., Youdan J., Barden R., Kasprzyk-Hordern B. 2016. New Framework To Diagnose the Direct Disposal of Prescribed Drugs in Wastewater - A Case Study of the Antidepressant Fluoxetine. Environ. Sci. Technol., 50, 3781-3789. https://doi. org/10.1021/acs.est.6b00291

21. Piovesan J., Santana E., Spinelli A. 2018. Reduced graphene oxide/gold nanoparticles nanocompositemodified glassy carbon electrode for determination of endocrine disruptor methylparaben. J. electroanal. chem., 813, 163-170. https://doi.org/10.1016/j. jelechem.2018.02.025

22. Sanusi S.N.A., Halmi M.I.E., Abdullah S.R.S., Hassan H.A., Hamzah F.M., Idris M. 2016. Comparative process optimization of pilot-scale total petroleumhydrocarbon (TPH) degradation by Paspalum scrobiculatum L. Hackusing response surface methodology (RSM) and artificial neuralnetworks (ANNs). Ecol. Eng. 97, 524-534. http://dx.doi.org/10.1016/j. ecoleng.2016.10.044

23. Teiri H., Hajizadeh Y., Samaei M.R., Pourzamani H., Mohammadi F. 2020. Modelling the phytoremediation of formaldehyde from indoor air by Chamaedorea Elegans using artificial intelligence, genetic algorithm and response surface methodology. J. Environ. Chem. Eng., 8, 103985. https://doi. org/10.1016/j.jece.2020.103985

24. Thani N.S.M., Ghazi R.M., Abdul Wahab I.R., Amin M.F.M., Hamzah Z., Yuso N.R.N. 2020. Optimization of Phytoremediation of Nickel by Alocasia puber Using Response Surface Methodology. Water 12, 2707. http://doi:10.3390/w12102707

25. Ting W.H.T., Tan I.A.W., Salleh S.F., Abdul Wahab N. 2020. Ammoniacal nitrogen removal by Eichhornia crassipes-based phytoremediation: process optimization using response surface methodology. Appl. Water Sci. 10, 80. https://doi.org/10.1007/ s13201-020-1163-x

26. Titah H.S., Halmi M.I.E.B., Abdullah S.R.S., Hasan H.A., Idris M., Anuar N. 2018. Statistical optimization of the phytoremediation of arsenic by Ludwigia octovalvis- in a pilot reed bed using response surface methodology (RSM) versus an artificial neural network (ANN). Int. J. Phytoremediation, 20, 721-729. https://doi.org/10.1080/15226514.2017. 1413337.

27. United States Pharmacopeia and National Formulary (USP 29 NF 24). 2006. Rockville, MD: United States Pharmacopeia Convention, 2, 3711.

28. Vymazal J., Dvořáková Březinová T., Koželuh M., Kule L. 2017. Occurrence and removal of pharmaceuticals in four full-scale constructed wetlands in the Czech Republic - the first year of monitoring. Ecol. Eng., 98, 354-364. https://doi.org/10.1016/j. ecoleng.2016.08.010

29. Wang S., Yu J., Guo F., Pan G., Zhang L., Hu H., Lu Y., Dao G. 2020. Optimization of Combined Submerged Macrophyte Planting Conditions for Inhibiting Algae by Response Surface Methodology. Water 12, 2093. https://doi.org/10.3390/w12082093

30. Weerakoon G.M.P.R., Jinadasa K.B.S.N., Manatunge J., Wijesiri B., Goonetilleke A. 2020. Kinetic modelling and performance evaluation of vertical subsurface flow constructed wetlands in tropics. J. Water Process. Eng. 38, 101539. https://doi. org/10.1016/j.jwpe.2020.101539

31. Williams M., Kookana R.S., Mehta A., Yadav S.K., Tailor B.L., Maheshwari B. 2019. Emerging contaminants in a river receiving untreated wastewater from an Indian urban centre. Sci. Total Environ. 647, 1256-1265. https://doi.org/10.1016/j. scitotenv.2018.08.084.

32. Xu M., Huang H., Li N., Li F., Wang D., Luo Q. 2019. Occurrence and Ecological Risk of Pharmaceuticals and Personal Care Products (PPCPs) and Pesticides in Typical Surface Watersheds, China. Ecotoxicol. Environ. Saf., 175, 289-298. https:// doi.org/10.1016/j.ecoenv.2019.01.131. 